\title{
Ytterbium-Doped Tantalum Pentoxide Waveguides: Spectroscopy for Compact Waveguide Lasers
}

\author{
A. Aghajani ${ }^{1 *}$, G. S. Murugan ${ }^{1}$, N. P. Sessions ${ }^{1}$, V. Apostolopoulos ${ }^{2}$, J. S. Wilkinson ${ }^{1}$ \\ ${ }^{1}$ Optoelectronics Research Centre, University of Southampton, Southampton, UK SO17 1BJ \\ ${ }^{2}$ School of Physics and Astronomy, University of Southampton, Southampton, UK SO17 1BJ \\ *aa15v07@soton.ac.uk
}

\begin{abstract}
Ytterbium-doped materials are common gain media in high-performance laser systems. In this work, the first spectroscopic investigation of ytterbium-doped tantalum pentoxide (Yb:Ta2O5) for compact waveguide laser applications is presented.

OCIS codes: (140.3615) Lasers, ytterbium; (230.7380) Waveguides, channeled
\end{abstract}

\section{Introduction}

Integrated channel waveguide solid-state lasers are key components in the quest for fully integrated optical circuits with advanced functionality such as tunability and pulsed operation. $\mathrm{Ta}_{2} \mathrm{O}_{5}$ has been selected as the host material for the realization of a compact, integrated ytterbium doped waveguide laser as it offers many important attributes such as good ability to host rare-earth ions, as demonstrated with erbium [1] and neodymium [2], a large third nonlinearity [3] and a high refractive index $(\mathrm{n} \approx 2.124$ at $\lambda \approx 980 \mathrm{~nm})$ [4]. High index contrast between the waveguide cladding and core provides for low-loss tight bend radii enabling the development of compact and ultrasmall photonic circuits due to the strong confinement of the optical modes, and offers the potential for 2-D photonic crystal operation.

$\mathrm{Ta}_{2} \mathrm{O}_{5}$ thin films also have excellent mechanical and thermal properties and have great compatibility with complementary-metal-oxide-semiconductor (CMOS) technologies making it an ideal candidate for mass producible integrated optical circuits.

In this work, we present for the first time the initial spectroscopic findings for $\mathrm{Yb}_{\mathrm{Ta}} \mathrm{Ta}_{2} \mathrm{O}_{5}$ rib waveguides and quantify the absorption cross section and fluorescence spectrum for this $\mathrm{Yb}_{\mathrm{T}} \mathrm{Ta}_{2} \mathrm{O}_{5}$ material.

\section{Waveguide design and fabrication}

Suitable dimensions for single mode (SM) operation of rib waveguides in tantalum pentoxide at a wavelength of 980 $\mathrm{nm}$ were determined using the method outlined in [5], and were confirmed using finite element modelling (COMSOL), Figure $1 \mathrm{~b}$. A $1 \mu \mathrm{m}$ rib height with an etch depth of $150 \mathrm{~nm}$ was predicted to yield SM operation at widths up to $1.9 \mu \mathrm{m}$, and a cross-sectional diagram of the waveguide design is shown in Figure 1a.
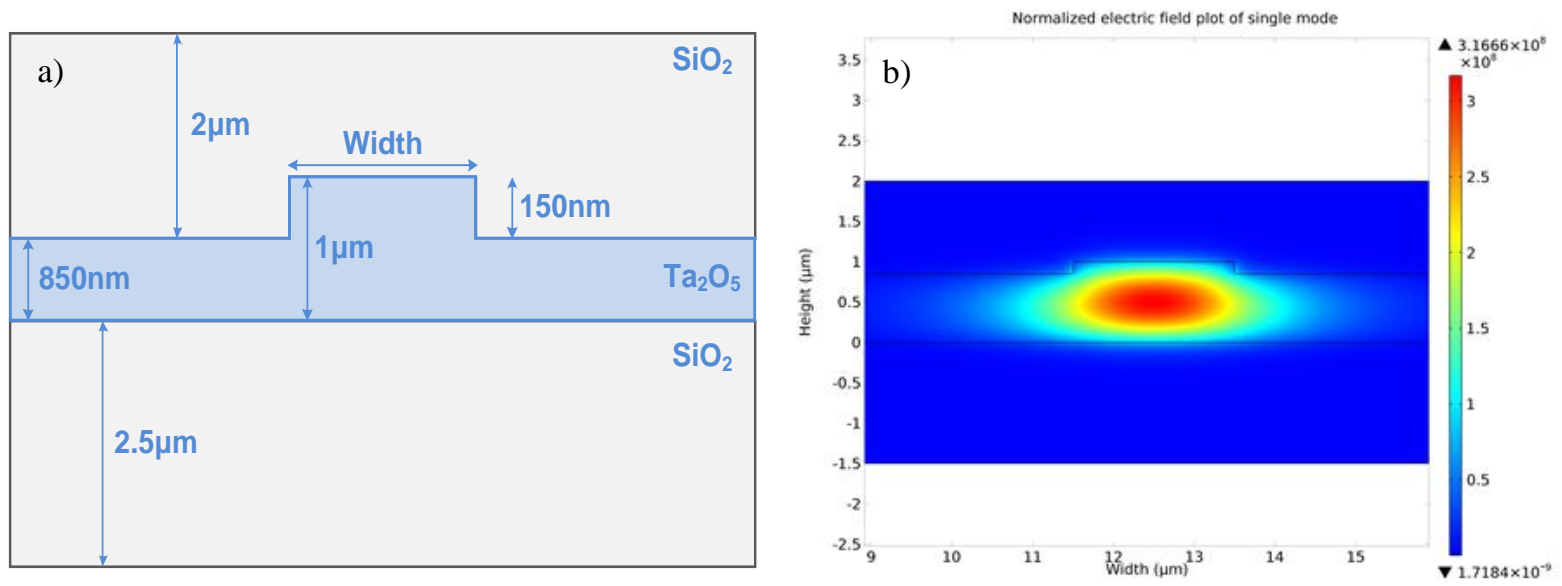

Figure 1a) Rib waveguide structure cross-section dimensions b) COMSOL simulation of a mode intensity profile of rib waveguide

$\mathrm{Yb}: \mathrm{Ta}_{2} \mathrm{O}_{5}$ slab waveguides were fabricated by RF magnetron sputter deposition from a powder-pressed tantalum pentoxide target, doped with $2.5 \mathrm{wt} \%$ of ytterbium $\left(\sim 6.2 \times 10^{20}\right.$ atoms $\left./ \mathrm{cm}^{3}\right)$ onto a silicon substrate with $2.5 \mu \mathrm{m}$ predeposited silica layer. The $\mathrm{Yb}: \mathrm{Ta}_{2} \mathrm{O}_{5}$ was deposited using conditions of $200{ }^{\circ} \mathrm{C}$ substrate temperature, $300 \mathrm{~W}$ of magnetron power, and 20 and $5 \mathrm{sccm}$ of argon and oxygen gas flow. For the development of rib structures a 
combination of photolithography and argon ion beam milling (IBM) was used. The mask pattern used for photolithography consisted of straight channels of width varying from 1 to $10 \mu \mathrm{m}$ in $0.2 \mu \mathrm{m}$ steps, with $100 \mu \mathrm{m}$ spacing. This defined the channel waveguide mask for the argon IBM process. After the rib structure was etched into the $\mathrm{Yb}: \mathrm{Ta}_{2} \mathrm{O}_{5}$ film, a $2 \mu \mathrm{m}$ of silica was deposited to encapsulate the waveguide core, producing a symmetrical channel waveguide.

\section{Spectral characterization}

Measurement of the absorption spectrum of a broad ytterbium-doped rib waveguide was performed to allow for the accurate determination of ytterbium absorption cross sections at the pump ( 980 nm) wavelength. The absorption spectrum of the $\mathrm{Yb}: \mathrm{Ta}_{2} \mathrm{O}_{5}$ was determined through broadband (700-1700 nm) white light measurements using light from a tungsten halogen lamp. The light from the lamp was coupled to a $3 \mathrm{~mm}$ long, end-facet polished $\mathrm{Yb}^{\mathrm{T}} \mathrm{Ta} \mathrm{O}_{5}$ rib waveguide sample. The waveguide with the widest width was selected to ensure that the majority of the power travelled in the $\mathrm{Yb}: \mathrm{Ta}_{2} \mathrm{O}_{5}$ core material rather than in the cladding, so that the absorption measurement was an accurate reflection of the $\mathrm{Yb}: \mathrm{Ta}_{2} \mathrm{O}_{5}$ material. Light was coupled out of the waveguide using a multimode fiber into an optical spectrum analyzer (OSA).

The resulting spectrum is shown in Figure 2a, where the prominent absorption bands of ytterbium at 935 and $975 \mathrm{~nm}$ are clearly visible. The peak absorption cross section for ytterbium ions in $\mathrm{Ta}_{2} \mathrm{O}_{5}$ in the pump band occurred at $975 \mathrm{~nm}$ and was calculated to be $2.75 \times 10^{-20} \mathrm{~cm}^{2}$, using an estimated concentration of the Ytterbium ions in the $\mathrm{Ta}_{2} \mathrm{O}_{5}\left(\sim 6.2 \times 10^{20} \mathrm{~cm}^{-3}\right)$, that is assuming that the film composition is the same as the sputtering target concentration.
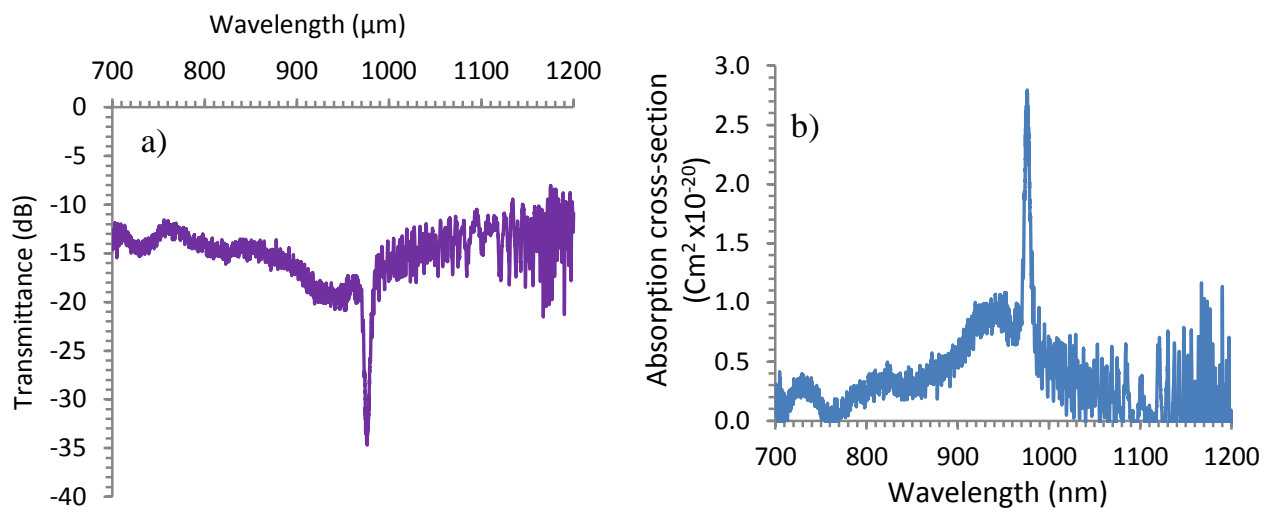

Figure 2a) $\mathrm{Yb}: \mathrm{Ta}_{2} \mathrm{O}_{5}$ absorption spectrum b) $\mathrm{Yb}: \mathrm{Ta}_{2} \mathrm{O}_{5}$ absorption cross-section

The fluorescence spectrum of the $\mathrm{Yb}: \mathrm{Ta}_{2} \mathrm{O}_{5}$ waveguide was also obtained to quantify the peak emission wavelength and the bandwidth. The apparatus for measuring the fluorescence spectrum consisted of a $977 \mathrm{~nm}$ fiber Bragg grating laser source, fiber butt-coupled with a single mode fiber into end-facet of the $\mathrm{Yb}_{\mathrm{T}} \mathrm{Ta}_{2} \mathrm{O}_{5}$ waveguide. Waveguides with widths below $2 \mu \mathrm{m}$ were found to be single moded at $977 \mathrm{~nm}$. The output light was collected using a multi-mode fiber positioned vertically above the waveguide near the waveguide input, and this was fed into an Optical Spectrum Analyser (OSA). The resulting fluorescence spectrum is shown in Figure 3, along with the input pump power from the laser diode measure without a sample. From the collected spectrum it is evident that there are three interesting regions shown, the first region indicates fluorescence peaks at wavelengths of $972 \mathrm{~nm}$ and $976 \mathrm{~nm}$ at peak pump wavelength of $971 \mathrm{~nm}$, while the second region shows broad fluorescence band between $900 \mathrm{~nm}$ and $1135 \mathrm{~nm}$. The last significant region at a wavelength of $744 \mathrm{~nm}$ is the most unexpected of the three regions. This is because the wavelength $744 \mathrm{~nm}$ corresponding to a wavenumber of $13440.86 \mathrm{~cm}^{-1}$ is not evident in the $\mathrm{Yb}^{3+}$ energy level diagram. Similar emission of wavelength was also shown by Paschotta et al. [6], citing that this could be caused by $\mathrm{Ge}-\mathrm{O}$ defects leading to the weak board-band fluorescence around $744 \mathrm{~nm}$. 


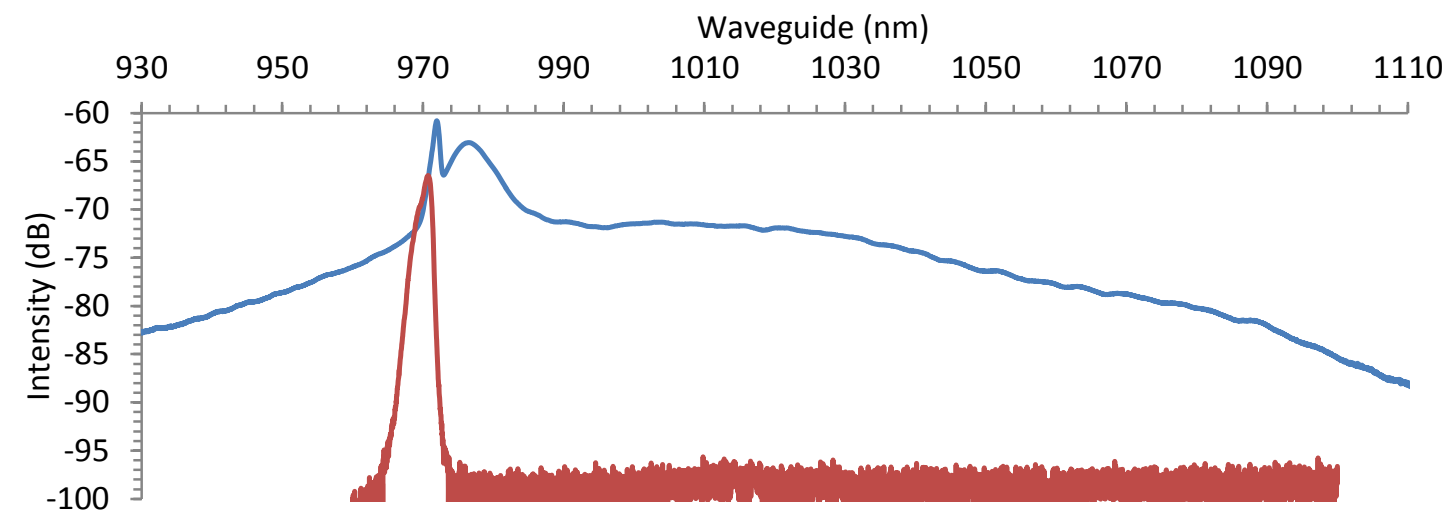

Figure 3 Fluorescence Spectrum $\mathrm{Yb}: \mathrm{Ta}_{2} \mathrm{O}_{5}$ waveguide: blue spectrum of $\mathrm{Yb}: \mathrm{Ta}_{2} \mathrm{O}_{5}$ fluorescence; red spectrum of pump source

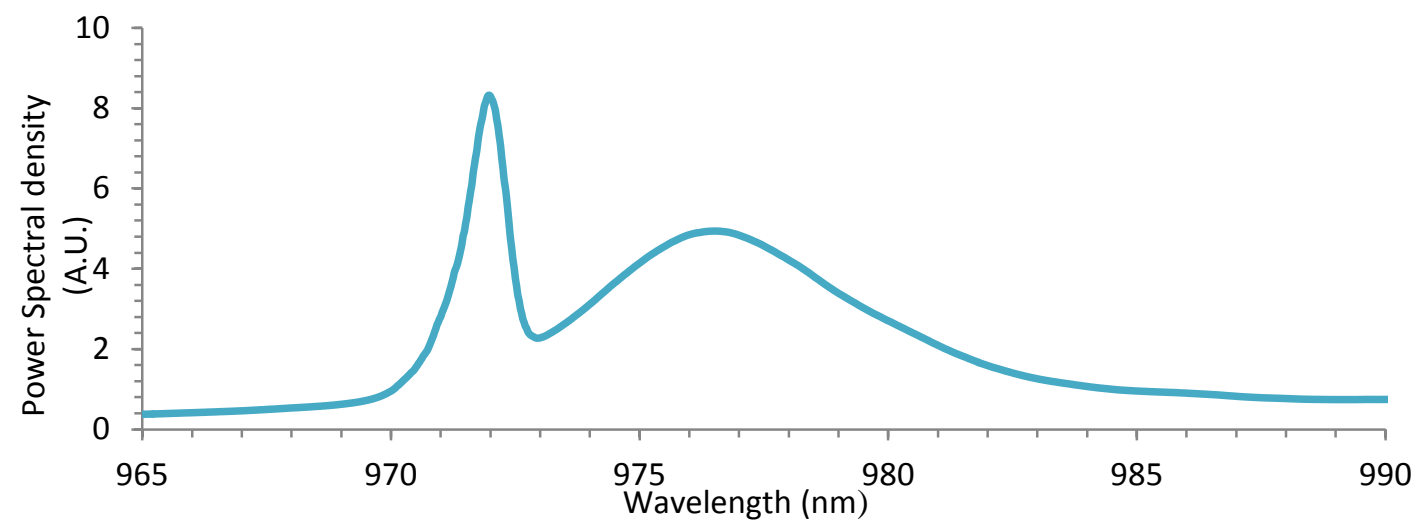

Figure 4 Fluorescence power density spectrum of $\mathrm{Yb}_{\mathbf{T}} \mathrm{Ta}_{2} \mathrm{O}_{5}$

\section{Conclusion}

In conclusion, $\mathrm{Yb}: \mathrm{Ta}_{2} \mathrm{O}_{5}$ waveguides operating in a single mode at a wavelength of $977 \mathrm{~nm}$ for widths less than $2 \mu \mathrm{m}$ were realised on silicon substrates and the absorption and fluorescence spectra obtained. The peak absorption crosssection was measured to be $2.75 \times 10^{-20} \mathrm{~cm}^{2}$ and the emission spectrum was found to be typical of $\mathrm{Yb}$-doped materials in the wavelength region around $1 \mu \mathrm{m}$. This material system shows promise for advanced compact lasers with monolithically integrated components to add functionality, such as ring resonators exploiting the high index contrast and nonlinear components for switching, exploiting the high $\chi^{(3)}$ of tantala. The CMOS-compatible nature of the processes used to fabricate these waveguides offers a potential route to low-cost mass production of these lasers.

\section{References}

[1] A. Z. Subramanian, C. J. Oton, D. P. Shepherd and J. S. Wilkinson, "Erbium-Doped Waveguide Laser in Tantalum," IEEE Photonics Technology Letters, vol. 22, no. 21, pp. 1571-1573, 2010.

[2] B. Unal, M. C. Netti, M. A. Hassan, P. J. Ayliffe, M. D. B. Charlton, F. Lahoz, N. M. B. Perney, D. P. Shepherd, C.-Y. Tai, J. S. Wilkinson and G. J. Parker, "Neodymium-doped tantalum pentoxide waveguide lasers," IEEE Journal of Quantum Electronics, vol. 41, no. 12, pp. 1565 $-1573,2005$.

[3] C. Y. Tai, J. S. Wilkinson, N. M. B. Perney, M. C. Netti, F. Cattaneo, C. E. Finlayson and J. J. Baumberg, "Determination of nonlinear refractive index in a Ta2O5 rib waveguide using self-phase modulation," Optics Express, vol. 21, pp. 5110 -5116, 2004.

[4] A. Subramanian, "Tantalum Pentoxide Waveguide Amplfier and Laser for Planar Lightwave Circuits," University of Southampton, ORC, Southampton, 2011.

[5] R. Soref, J. Schmidtchen and K. Petermann, "Large single-mode rib waveguides in GeSi-Si and Si-on-SiO2," IEEE Journal of Quantum Electronics, vol. 27, no. 8, pp. 1971-1974, 1991.

[6] R. Paschotta, J. Nilsson, P. Barber, J. Caplen, A. Tropper and D. Hanna, "Lifetime quenching in Yb-doped fibres," Optics Communications, vol. 136, no. 5-6, p. 375-378, 1997. 